\title{
2,3-Diarylxanthones as Potential Inhibitors of Arachidonic Acid Metabolic Pathways
}

\author{
Clementina M. M. Santos, ${ }^{1,2,4}$ Daniela Ribeiro, ${ }^{3}$ Artur M. S. Silva, ${ }^{2}$ and Eduarda Fernandes ${ }^{3,4}$
}

\begin{abstract}
In response to an inflammatory stimulus, arachidonic acid (AA), the main polyunsaturated fatty acid present in the phospholipid layer of cell membranes, is released and metabolized to a series of eicosanoids. These bioactive lipid mediators of inflammation arise physiologically through the action of the enzymes 5-lipoxygenase (5-LOX) and cyclooxygenases (constitutive COX-1 and inducible COX-2). It is believed that dual inhibition of 5-LOX and COXs may have a higher beneficial impact in the treatment of inflammatory disorders rather than the inhibition of each enzyme. With this demand for new dual-acting antiinflammatory agents, a range of 2,3-diarylxanthones were tested through their ability to interact in the AA metabolism. In vitro anti-inflammatory activity was evaluated through the inhibition of 5-LOX-catalyzed leukotriene $\mathrm{B}_{4}\left(\mathrm{LTB}_{4}\right)$ formation in human neutrophils and inhibition of COX-1- and COX-2-catalyzed prostaglandin $\mathrm{E}_{2}\left(\mathrm{PGE}_{2}\right)$ formation in human whole blood. The results showed that some of the studied arylxanthones were able to prevent $\mathrm{LTB}_{4}$ production in human neutrophils, in a concentration-dependent manner. The xanthone with a 2-catechol was the most active one $\left(\mathrm{IC}_{50} \sim 9 \mu \mathrm{M}\right)$. The more effective arylxanthones in preventing COX-1-catalyzed $\mathrm{PGE}_{2}$ production presented $\mathrm{IC}_{50}$ values from 1 to $7 \mu \mathrm{M}$, exhibiting a structural feature with at least one non-substituted aryl group. All the studied arylxanthones were ineffective to prevent the formation of $\mathrm{PGE}_{2}$ catalyzed by COX-2, up to the maximum concentration of $100 \mu \mathrm{M}$. The ability of the tested 2,3-diarylxanthones to interact with both 5-LOX and COX-1 pathways constitutes an important step in the research of novel dual-acting anti-inflammatory drugs.
\end{abstract}

KEY WORDS: xanthones; 5-LOX; COX-1; COX-2; human neutrophils; human whole-blood assay.

\section{INTRODUCTION}

Inflammation is the natural response of the organism to tissue damage, most of the times arising from physical or

\footnotetext{
${ }^{1}$ School of Agriculture, Polytechnic Institute of Bragança, Campus de Santa Apolónia, 5300-253 Bragança, Portugal

${ }^{2}$ Department of Chemistry \& QOPNA, University of Aveiro, Campus de Santiago, 3810-193 Aveiro, Portugal

${ }^{3}$ UCIBIO, REQUIMTE, Applied Chemistry Laboratory, Department of Chemical Sciences, Faculty of Pharmacy, University of Porto, Rua de Jorge Viterbo Ferreira, 228, 4050-313 Porto, Portugal

${ }^{4}$ To whom correspondence should be addressed to Clementina Santos at Department of Chemistry \& QOPNA, University of Aveiro, Campus de Santiago, 3810-193 Aveiro, Portugal. E-mail: clems@ipb.pt; and Eduarda Fernandes at UCIBIO, REQUIMTE, Applied Chemistry Laboratory, Department of Chemical Sciences, Faculty of Pharmacy, University of Porto, Rua de Jorge Viterbo Ferreira, 228, 4050313 Porto, Portugal. E-mail: egracas @ff.up.pt
}

chemical irritations, infections caused by a pathogen, or other injuries. It is also part of a complex physiological protective response to harmful stimuli in a body's attempt to heal itself, through the elimination of the initial cause of cell injury, removing necrotic cells and tissues, and initiating the process of repair. The inflammatory response is induced by chemical mediators produced locally by damaged cells at the site of inflammation or derived from circulating inactive precursors (typically synthesized by the liver) that are activated at the referred site [1]. There are two types of chemical mediators: cell-derived mediators that include histamine and serotonin (preformed mediators in secretory granules) and mediators synthesized as needed such as arachidonic acid (AA) metabolites (leukotrienes, prostaglandins, and platelet-activating factor), cytokines, and nitric oxide; and plasma-derived mediators which include complement activation system, kinin 
system, and coagulation/fibrinolysis system [2]. These mediators are involved in the activation of resident cells such as endothelial and epithelial cells and/or the recruitment and activation of inflammatory cells such as macrophages, monocytes, and neutrophils [1]. Two of these proinflammatory mediators are leukotrienes and prostaglandins that arise via arachidonic acid metabolism. The first step is the hydrolysis of this 20-carbon polyunsaturated fatty acid present in the phospholipid layer of cell membranes, catalyzed by the enzyme phospholipase $\mathrm{A}_{2}$. Then, free AA can be metabolized by several lipoxygenases (LOXs), leading to the formation of a series of hydroxy acids and leukotrienes. In mammalian tissues, 5-LOX is generally found in cells of myeloid origin, like polymorphonuclear leukocytes, activated macrophages, and mast cells, and it is the main enzyme implicated in inflammatory and allergic disorders. The metabolism of AA can also involve the formation of prostaglandins through the action of membrane protein cyclooxygenase (COX, also known as prostaglandin $\mathrm{H}$ synthase). Two isoforms of COX are implicated in the inflammatory process: COX-1, which is constitutively expressed within most tissues and responsible for the normal physiological production of prostaglandins, and COX2 , that although absent in most normal tissues is highly induced by several inflammatory and mitogenic cells and is responsible for the overproduction of prostaglandins during inflammation [3].

Non-steroidal anti-inflammatory drugs (NSAIDs) are among the most common medicines used to restrain the characteristic signs of an inflammatory process. Nonetheless, drawbacks such as gastrointestinal disorders and renal damage limit their use. An alternative strategy is the use of selective COX-2 inhibitors that decreases these effects but is associated to cardiac implications [4]. Thus, many efforts have been made in order to develop the so-called dualacting anti-inflammatory drugs able to inhibit both 5-LOX and COXs, maintaining the activity of classical NSAIDs while avoiding their side effects $[5,6]$.

Xanthones (9H-xanthen-9-ones) are an important class of oxygenated heterocyclic compounds widespread in nature. The pharmacological properties of both natural and synthetic xanthones (e.g., anti-inflammatory, antimalarial, antioxidant, and antitumour activities) are associated to different substituents in different positions of their main core [7-12]. Aryl groups linked to xanthones are scarce in natural sources, but several publications reporting their synthesis and/or biomedical potential have been highlighted in literature and reviewed in [13]. In fact, the hydroxylated 2,3-diarylxanthones studied in the present work were already described as capable of scavenging oxygen and nitrogen reactive species $[14,15]$ and inhibiting lipid peroxidation [16]. As so, they can be seen as excellent candidates to act as modulators of the inflammatory process. The present investigation was undertaken to evaluate the interaction of a range of 2,3-diarylxanthones in the AA metabolism regarding their interference in the 5-LOX enzyme activity, namely through the inhibition of leukotriene $\mathrm{B}_{4}$ $\left(\mathrm{LTB}_{4}\right)$ production in human neutrophils, and COX-1 and COX-2 enzyme activities, specifically through the inhibition of prostaglandin $\mathrm{E}_{2}\left(\mathrm{PGE}_{2}\right)$ production in human whole blood.

\section{MATERIAL AND METHODS}

\section{Reagents, Chemicals, and Equipment}

All chemicals and solvents used were of analytical grade, obtained from commercial sources, and used as received. Acetylsalicylic acid, arachidonic acid (AA), calcium ionophore (A23187), chremophor ${ }^{\circledR}$ EL, dimethyl sulfoxide (DMSO), gentamicin sulfate, Hank's balanced salt solution (HBSS), lipopolysaccharides from Escherichia coli 026:B6 (LPS), methanol, nordihydroguaiaretic acid (NDGA), and trypan blue solution $0.4 \%$ were obtained from SigmaAldrich Co. LLC (St. Louis, USA). The thromboxane synthase inhibitor (TXBSI) was synthesized as previously described [17]. The "Leukotriene B4 Enzyme Immunoassay (EIA) Kit" was obtained from Cayman Chemical (Ann Arbor, MI). The "PGE2 EIA Kit" was obtained from Enzo Life Sciences (Lausen, Switzerland). 2,3-Diarylxanthones 1-3 (Fig. 1) were synthesized according to a previously described procedure [18].

A multimode microplate reader (Synergy HT, BIOTEK) with temperature control capacity was used to perform the spectrophotometric readings in all the assays.

\section{5-LOX-Neutrophil Assay}

\section{Isolation and Treatment of Human Neutrophils}

Following informed consent, neutrophils were isolated from venous blood collected from healthy human volunteers, by antecubital venipuncture, into $\mathrm{K}_{3}$ EDTA vacuum tubes. The isolation of the human neutrophils was performed by the density gradient centrifugation method as previously described [19]. Cell viability and cell yield were evaluated by the trypan blue exclusion method, using a Neubauer chamber and an optic microscope with $\times 40$ magnification. HBSS was used as the incubation medium and the isolated neutrophils' suspensions were kept on ice 


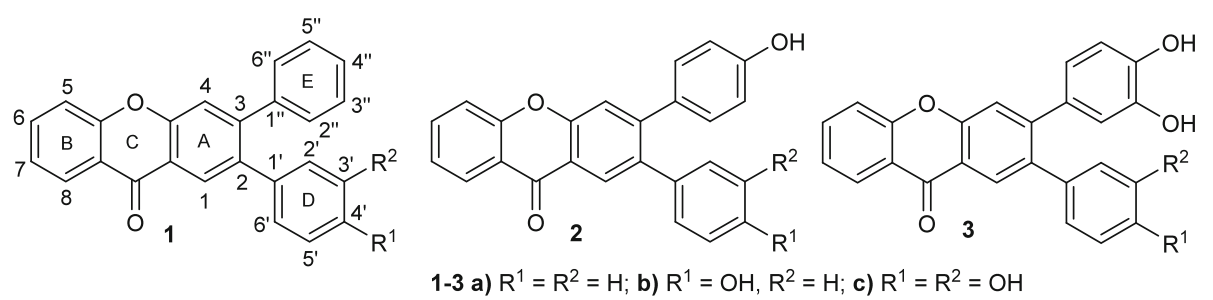

Fig. 1. Chemical structures of the tested 2,3-diarylxanthones 1-3.

until use. Neutrophils' suspensions $\left(3.5 \times 10^{6}\right.$ cells $\left./ \mathrm{mL}\right)$ in HBSS were placed in 96-well microplates $(140 \mu \mathrm{L} /$ well $)$ at $37^{\circ} \mathrm{C}$ for $10 \mathrm{~min}$ to equilibrate. The tested xanthones (1.0$20 \mu \mathrm{M})$, dissolved in a (9:1) mixture of HBSS:DMSO, were then added and pre-incubated for $10 \mathrm{~min}$. The cells were subsequently incubated with A23187 $(5 \mu \mathrm{M})$ and AA $(10 \mu \mathrm{g} / \mathrm{mL})$ for $8 \mathrm{~min}$. The reactions were stopped by the addition of cold methanol. Samples were subsequently centrifuged at $13,000 \times g$ for 5 min at $4{ }^{\circ} \mathrm{C}$ and the supernatants were collected and stored at $-20^{\circ} \mathrm{C}$ until use [20]. The quantity of solvents used did not have inhibitory effects and neither affected the cellular viability.

\section{Determination of $\mathrm{LTB}_{4}$ Production in Human Neutrophils}

The amount of $\mathrm{LTB}_{4}$ in the collected supernatants was measured using the above mentioned commercial EIA kit, according to the manufacturer's instructions. The 5-LOX inhibitor, NDGA $(1 \mu \mathrm{M})$, was used as positive control. The results were expressed as the percent inhibition of control $\mathrm{LTB}_{4}$ production. At least three independent experiments were performed to each assay.

\section{COXs-Human Whole-Blood Assay}

\section{COX-1 Assay}

Following informed consent, venous blood was collected from healthy human volunteers, by antecubital venipuncture, into heparin- $\mathrm{Li}^{+}$vacuum tubes. The human whole-blood assay to assess the COX-1 inhibition was performed as previously reported [21,22]. Collected blood $(500 \mu \mathrm{L})$ was placed in microtubes and incubated in a water bath at $37{ }^{\circ} \mathrm{C}$ with TXBSI $(1 \mu \mathrm{M})$ and the tested xanthones $(0.312-100 \mu \mathrm{M})$ dissolved in DMSO for $15 \mathrm{~min}$. Then, the A23187 $(12.2 \mu \mathrm{g} / \mathrm{mL})$ was added and the mixture was incubated for $15 \mathrm{~min}$, allowing the triggering of COX-1 activity. The reactions were stopped putting the samples on ice for $5 \mathrm{~min}$, followed by centrifugation at $1000 \times g$ for $20 \mathrm{~min}$ at $4{ }^{\circ} \mathrm{C}$. The supernatants were then collected and stored at $-20{ }^{\circ} \mathrm{C}$ until use. The quantity of solvents used did not have inhibitory effects and neither affected the cellular viability.

\section{COX-2 Assay}

The human whole-blood assay to assess the COX-2 inhibition was performed as previously described, with modifications [22, 23]. Collected blood $(800 \mu \mathrm{L})$ was placed in six-well plates and incubated for $15 \mathrm{~min}$ in a humidified incubator at $37{ }^{\circ} \mathrm{C}$ with TXBSI $(1 \mu \mathrm{M})$, acetylsalicylic acid $(10 \mu \mathrm{g} / \mathrm{mL})$, and the tested xanthones $(1-100 \mu \mathrm{M})$, dissolved in a $(1: 10)$ mixture of DMSO:(chremophor/ethanol 1\%). Here, TXBSI reduces the amount of LPS needed and its incubation period. Then, LPS $(10 \mu \mathrm{g} / \mathrm{mL})$ was added and the mixture was incubated for $5 \mathrm{~h}$, allowing the activation of COX-2. The reactions were stopped by adding DPBS-gentamicin buffer $(1 \mathrm{~mL})$ to the samples and placing them on ice for $10 \mathrm{~min}$. Subsequently, the samples were centrifuged at $1000 \times g$ for $15 \mathrm{~min}$ at $4{ }^{\circ} \mathrm{C}$ and the supernatants were collected and stored at $-20{ }^{\circ} \mathrm{C}$ until use. The quantity of solvents used did not have inhibitory effects and neither affected the cellular viability.

\section{Determination of $P G E_{2}$ Production in Human Whole Blood}

The amount of $\mathrm{PGE}_{2}$ in the samples (thawed plasma supernatants) was measured using the above mentioned commercial EIA kit, according to the manufacturer's instructions, as an indicator of COX-1 and COX-2 activities. Indomethacin $(1 \mu \mathrm{M})$ and celecoxib $(10 \mu \mathrm{M})$ were used as positive controls for COX-1 and COX-2 assays, respectively. The results were expressed as the percent inhibition of control $\mathrm{PGE}_{2}$ production. At least three independent experiments were performed to each assay.

\section{Statistical Analysis}

Statistical analyses were calculated using the GraphPad Prism 6 software (GraphPad Inc., La Jolla, 
CA). The results were expressed as the percent inhibition of control $\mathrm{LTB}_{4}$ production [mean \pm standard error of the mean (SEM)]. $\mathrm{IC}_{50}$ values were calculated from the curves of percent inhibition of control $\mathrm{LTB}_{4}$ production or $\mathrm{PGE}_{2}$ production versus compound concentration. Statistical comparison between groups was estimated using the oneway analysis of variance (ANOVA), followed by the Bonferroni post hoc test. In all cases, $p$ values lower than 0.05 were considered as statistically significant.

\section{RESULTS}

\section{Inhibition of $\mathrm{LTB}_{\mathbf{4}}$ Production in Human Neutrophils}

All the tested xanthones were able to inhibit the 5LOX-LTB 4 production induced by A23187 and AA in human neutrophils, in a concentration-dependent manner (Fig. 2). It was only possible to calculate the $\mathrm{IC}_{50}$ value for the most active compounds, and regarding these results, the order of potencies found was as follows: $1 \mathrm{c}(9.2 \pm 4.1 \mu \mathrm{M})$, 1b $(11.6 \pm 4.6 \mu \mathrm{M}), 3 \mathbf{a}(13.5 \pm 0.6 \mu \mathrm{M})$, and $\mathbf{3 b}(13.7 \pm$ $2.1 \mu \mathrm{M})$ (Table 1).

At $20 \mu \mathrm{M}$, the highest tested concentration, xanthones $\mathbf{1 b}$ and $\mathbf{3 b}$ exhibited higher inhibitory rates of $71.1 \pm 6.8$ and $68.5 \pm 5.8 \%$, respectively. Xanthones $\mathbf{1 c}$ and $\mathbf{3 a}$ were also quite active with percentages of inhibition of $62.9 \pm$ 5.8 and $60.7 \pm 2.6 \%$, respectively, for $20 \mu \mathrm{M}$. The other tested xanthones presented activities lower than $50 \%$ up to $20 \mu \mathrm{M}$.

Overall, from compounds of group 1 , at $20 \mu \mathrm{M}$ concentration, derivative $\mathbf{1 b}(71.1 \pm 6.8 \%)$ was the most active, followed by $\mathbf{1 c}(62.9 \pm 5.8 \%)$ and $\mathbf{1 a}(40.5 \pm 6.9 \%$ of inhibition). All xanthones from group 2 were generally less active than the other tested xanthones, being derivative $2 \mathbf{c}$ the best of its group $(60.7 \pm 2.6 \%$ of inhibition). From group 3, xanthone $3 \mathbf{b}(68.5 \pm 5.8 \%)$ was the most active one, followed by $3 \mathbf{a}(60.7 \pm 2.6 \%)$ and $3 \mathbf{c}(46.7 \pm 1.2 \%$ of inhibition).

NDGA was used as positive control and showed an inhibitory activity of $47.7 \pm 3.5 \%$, for a concentration of $1 \mu \mathrm{M}$ (Table 1).

\section{Inhibition of $\mathrm{PGE}_{\mathbf{2}}$ Production in Human Whole Blood}

In what concerns inhibition of $\mathrm{COX}-1-\mathrm{PGE}_{2}$ production stimulated by $\mathrm{A} 23187$, the most active compounds were compounds $\mathbf{2 a}, \mathbf{1 a}$, and $\mathbf{1 b}\left(\mathrm{IC}_{50}=0.8 \pm 0.2,1.7 \pm 0.4\right.$, and $2.8 \pm 0.4 \mu \mathrm{M}$, respectively) (Table 1). Compounds 3a, $\mathbf{2 b}$, and $\mathbf{1 c}$ were also effective inhibitors with $\mathrm{IC}_{50}$ values of $6.6 \pm 1.1,15.8 \pm 3.3$, and $29.5 \pm 4.7 \mu \mathrm{M}$, respectively.

The results in terms of percentage of inhibition, to $10 \mu \mathrm{M}$ concentration, are in accordance with the $\mathrm{IC}_{50}$ values found. Thus, it is possible to establish two groups from the studied xanthones (Fig. 3). The first group includes the most active compounds, with inhibitory effects higher than $50 \%$ (for a concentration of $10 \mu \mathrm{M}$ ), in the

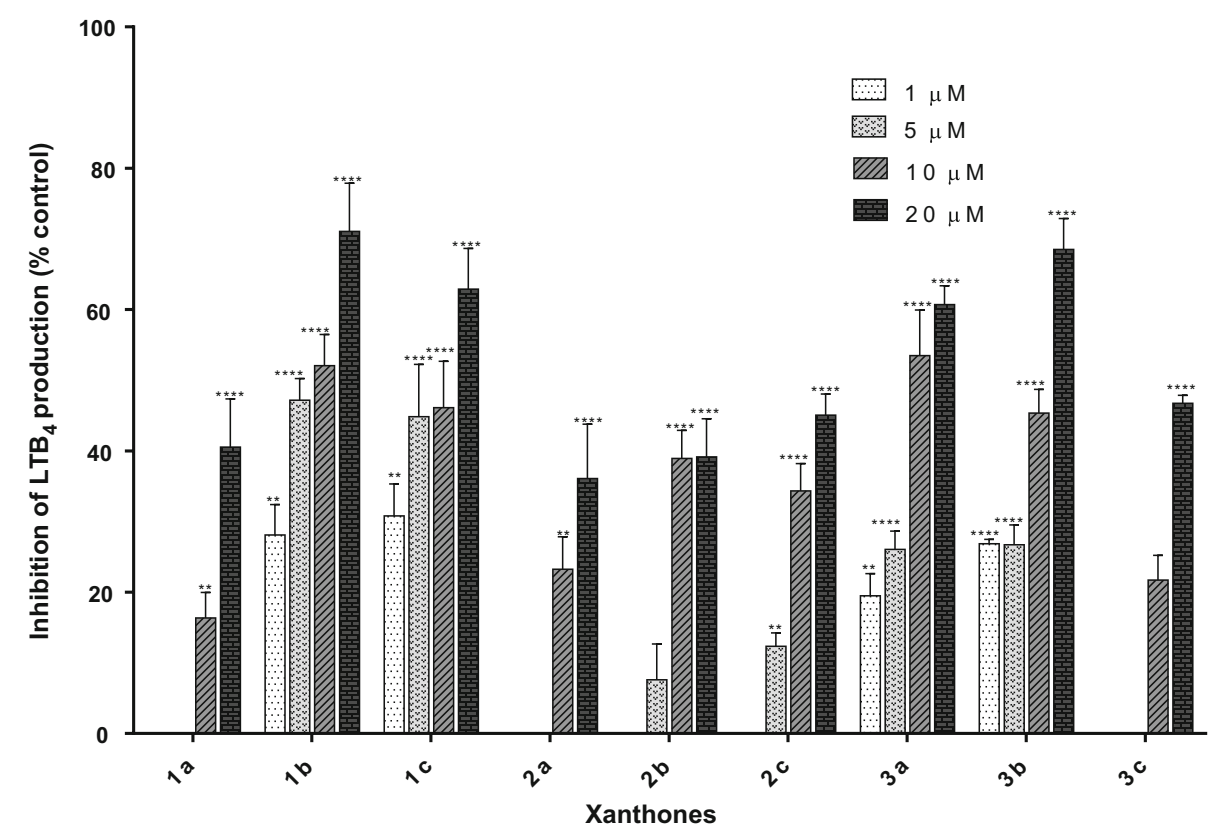

Fig. 2. Inhibition of $\mathrm{LTB}_{4}$ production induced by $\mathrm{A} 23187$ and AA in human neutrophils by the tested xanthones 1-3, determined by EIA. Each value represents the mean \pm SEM of at least three experiments. $* * * * P<0.0001, * * P<0.01$, compared to the stimulated control (A23187/AA). 
Table 1. Inhibitory Effects $\left(\mathrm{IC}_{50} \mu \mathrm{M}\right.$, mean $\left.\pm \mathrm{SEM}\right)$ of the Studied Xanthones 1-3 on the 5-LOX-LTB 4 Production in Human Neutrophils and COX-1$\mathrm{PGE}_{2}$ Production in Human Whole Blood. Each Study Corresponds to at Least Three Experiments

\begin{tabular}{|c|c|c|c|c|}
\hline \multirow{2}{*}{ Compounds } & \multirow{2}{*}{$\mathbf{R}^{1}$} & \multirow{2}{*}{$\mathbf{R}^{2}$} & \multicolumn{2}{|c|}{$\mathrm{IC}_{50}(\mu \mathrm{M}) \pm \mathrm{SEM}$} \\
\hline & & & 5-LOX & COX-1 \\
\hline $1 \mathbf{a}$ & $\mathrm{H}$ & $\mathrm{H}$ & ND & $1.7 \pm 0.4$ \\
\hline $1 b$ & $\mathrm{OH}$ & $\mathrm{H}$ & $11.6 \pm 4.6$ & $2.8 \pm 0.4$ \\
\hline $1 \mathrm{c}$ & $\mathrm{OH}$ & $\mathrm{OH}$ & $9.2 \pm 4.1$ & $29.5 \pm 4.7$ \\
\hline $2 \mathbf{a}$ & $\mathrm{H}$ & $\mathrm{H}$ & ND & $0.8 \pm 0.2$ \\
\hline $2 \mathbf{b}$ & $\mathrm{OH}$ & $\mathrm{H}$ & ND & $15.8 \pm 3.3$ \\
\hline $2 \mathrm{c}$ & $\mathrm{OH}$ & $\mathrm{OH}$ & ND & ND \\
\hline $3 \mathbf{a}$ & $\mathrm{H}$ & $\mathrm{H}$ & $13.5 \pm 0.6$ & $6.6 \pm 1.1$ \\
\hline $3 \mathbf{b}$ & $\mathrm{OH}$ & $\mathrm{H}$ & $13.7 \pm 2.1$ & ND \\
\hline $3 c$ & $\mathrm{OH}$ & $\mathrm{OH}$ & ND & ND \\
\hline $\begin{array}{l}\text { Positive contro } \\
\text { NDGA } \\
\text { Indomethacin }\end{array}$ & & & $\begin{array}{c}47.7 \pm 3.5^{1 \mu \mathrm{M}^{*}} \\
\mathrm{ND}\end{array}$ & $\begin{array}{c}\text { ND } \\
89.7 \pm 2.4^{1 \mu \mathrm{M}^{*}}\end{array}$ \\
\hline
\end{tabular}

$N D$ not determined

${ }^{a}$ The values represent the percentage of inhibition \pm SEM for the highest tested concentration (in superscript)

following order of potencies: $\mathbf{1 a}(91.4 \pm 2.1 \%)>\mathbf{2 a}(89.7$ $\pm 6.1 \%)>\mathbf{1 b}(78.8 \pm 7.1 \%)>\mathbf{3 a}(65.8 \pm 6.8 \%)$. In the second one are placed the xanthones with activities lower than $50 \%$, for $10 \mu \mathrm{M}$ concentration. Compounds $\mathbf{2 b}(38.2$ $\pm 4.9 \%)$ and $1 \mathrm{c}(22.1 \pm 7.2 \%)$ were the most active of this second group, being the other derivatives ineffective to inhibit the COX-1-PGE 2 production at this concentration. Nevertheless, xanthones $\mathbf{3 b}$ and $\mathbf{3} \mathbf{c}$ showed an inhibitory

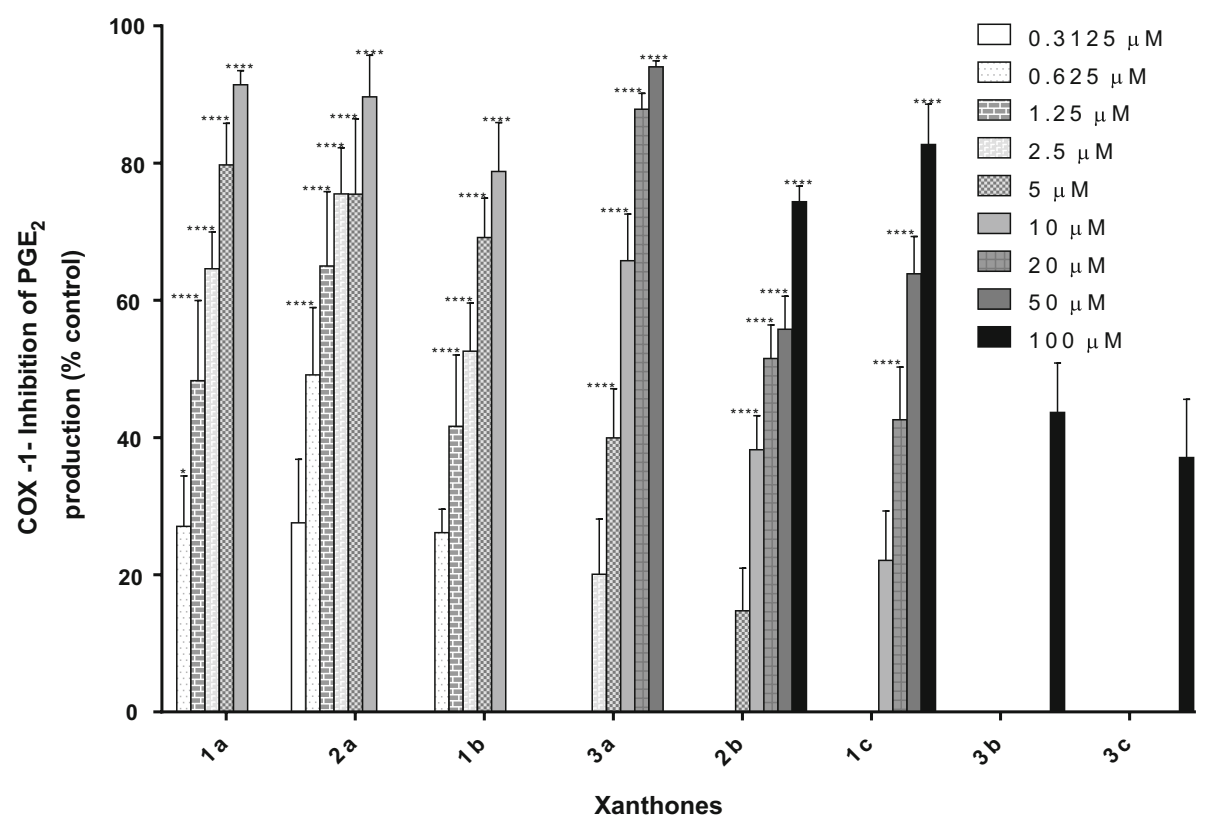

Fig. 3. Inhibition of COX-1 $\mathrm{PGE}_{2}$ production induced by $\mathrm{A} 23187$ in human whole blood by the xanthones 1-3 determined by EIA. Each value represents mean \pm SEM of at least three experiments. $* * * * P<0.0001, * P<0.1$, compared to the stimulated control (TXBSI/A23187). 
activity of $43.7 \pm 7.2$ and $37.1 \pm 8.5 \%$, respectively, for $100 \mu \mathrm{M}$, the highest tested concentration (Fig. 3).

Overall, among all the tested compounds, in a $10 \mu \mathrm{M}$ concentration, xanthones of group 1 were generally more active than the corresponding xanthones from the other groups, derivative 1a being the best of its group (91.4 \pm $2.1 \%$ inhibition). From group 2, xanthone 2a was the most active one ( $89.7 \pm 6.1 \%$ inhibition), followed by $\mathbf{2 b}$ (38.2 $\pm 4.9 \%$ inhibition), whereas $2 \mathbf{c}$ was not active, up to the highest tested concentration, $100 \mu \mathrm{M}$. Xanthone 3a (65.8 $\pm 6.8 \%$ inhibition) was the only effective inhibitor from group 3, the less active group of all the studied xanthones (Fig. 3). Indomethacin was used as positive control and showed an inhibitory activity of $89.7 \pm 2.4 \%$, for a concentration of $1 \mu \mathrm{M}$ (Table 1 ).

None of the studied xanthones 1-3 were able to inhibit COX-2-PGE 2 production induced by LPS in human whole blood, up to the highest tested concentration, $100 \mu \mathrm{M}$. Selective COX-2 inhibitor celecoxib $(10 \mu \mathrm{M})$ reached a $75.4 \pm 7.2 \%$ inhibitory effect.

\section{DISCUSSION}

The inhibition of 5-LOX pathway by the studied 2,3diarylxanthones 1-3 are reported here for the first time. All the studied compounds proved to be effective inhibitors of $\mathrm{LTB}_{4}$ production induced by A23187 and AA in human neutrophils at the concentration of $20 \mu \mathrm{M}$ (in a range of inhibition from 36 to $71 \%$ ). Generally, compounds of group 1 (non-substituted 3-phenyl ring) were the most active inhibitors while compounds of group 2 were the less active ones (possessing a 3-phenol group). An important structural feature for the higher inhibitory effect seems to be the presence of 2- or 3-catechol groups. Xanthone 1c (substituted with 2-catechol group and non-substituted 3phenyl ring) presented an $\mathrm{IC}_{50}$ value of around $9 \mu \mathrm{M}$. In fact, the presence of a catechol moiety in a wide variety of flavonoids has been described as vital for the inhibition of prooxidant enzymes like LOX [24, 25]. Moreover, Sadik et al. also pointed out that the inhibitory effect on 15-LOX enzyme by several flavonoids possessing a catechol unit correlates inversely with the number of other hydroxy groups in their skeleton [25]. The excessive number of hydroxy groups lowers the hydrophobicity of the compound and restrains their access to the active site of the enzyme. This feature can be an explanation for the lower inhibitory activity of compound $\mathbf{3 c}$ (the highly substituted tested xanthone) when compared to the other xanthones of group 3 .
Few studies have highlighted the potential antiinflammatory action of a range of xanthones; however, it is a hard task to make a comparison of results since different experimental conditions and enzyme sources are used. As examples of studies with natural xanthones, 1,3,6,7tetrahydroxyxanthone, a mangiferin aglycone known as norathyriol 4a (Fig. 4), suppressed A23187-induced $\mathrm{LTB}_{4}$ formation in rat neutrophils $\left(\mathrm{IC}_{50}=2.3 \pm 0.2 \mu \mathrm{M}\right)$ and in blood taken from pretreated mice to about $20 \%$ of corresponding control values [26]. Aqueous extract of Mangifera indica $\mathrm{L}$. and the glucosylxanthone mangiferin 4b (Fig. 2) isolated from this extract have also been tested for the A23187-induced $\mathrm{LTB}_{4}$ release in $\mathrm{J} 774$ murine macrophage [27] and RAW264.7 macrophage [28] cell lines. The purified compound showed a higher inhibitory effect $\left(\mathrm{IC}_{50}=2.1 \mu \mathrm{g} / \mathrm{mL}\right)$ than the extract $\left(\mathrm{IC}_{50}=26.0 \mu \mathrm{g} /\right.$ $\mathrm{mL}$ ) for $\mathrm{J} 774$ murine macrophages whereas mangiferin $\mathbf{4 b}$ at $10 \mu \mathrm{g} / \mathrm{mL}$ presented $68.8 \%$ of inhibition and the extract at $10 \mu \mathrm{g} / \mathrm{mL}$ showed $41.0 \%$ of inhibition of $\mathrm{LTB}_{4}$ production, for RAW264.7 macrophages. Crockett et al. isolated a furanoxanthone 5 (Fig. 4) from the roots of Hypericum perforatum and evaluated the inhibition of 5-LOXcatalyzed $\mathrm{LTB}_{4}$ formation in polymorphonuclear leukocytes. The results indicated an inhibition of $98.46 \pm$ $0.59 \%$ at $50 \mu \mathrm{g} / \mathrm{mL}(146 \mu \mathrm{M})$ and an $\mathrm{IC}_{50}$ of $10.2 \mu \mathrm{M}$ [29].

Several mechanisms can be associated to the inhibition of $\mathrm{LTB}_{4}$ production by flavonoids and phenolic compounds. It can include the inhibition of the enzyme phospholipase $\mathrm{A}_{2}$ and consequently the release of $\mathrm{AA}$, the inhibition of enzyme $\mathrm{LTA}_{4}$ hydrolase, the blockade of 5lipoxygenase-activating protein for leukotriene biosynthesis, and even direct inhibition of 5-LOX [20]. Werz and Steinhilber proposed that LOX inhibitors can be divided into redox-active compounds, iron-ligand inhibitors with weak redox-active properties, and non-redox-type inhibitors [30]. Examples of redox-active compounds are NGDA, coumarins, and flavonoids, but unfortunately, the former ones presented lack of selectivity in most cases and were rapidly metabolized. Hydroxamic acid and $N$-hydroxyurea derivatives act as iron-chelating inhibitors, but their hydroxamate group is easily metabolized in vivo and showed unfavorable pharmacokinetic properties. The classification of non-redox-type inhibitors is associated to the lack of redox activity of the drugs themselves but does not exclude that their inhibitory effect is influenced by the redox state of the target 5-LOX. Several compounds tested by oral administration proved to be selective to inhibit leukotriene biosynthesis in human leukocytes and whole blood but without success to inhibit their synthesis at sites of chronic inflammation $[24,30]$. As far as we know, no 


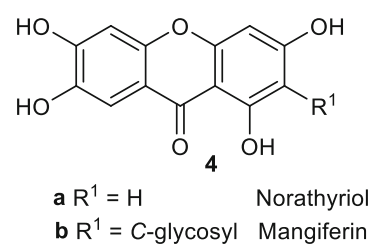<smiles>COc1c(O)ccc2c(=O)c3c(O)cc4c(c3oc12)C(C)(C)C(C)O4</smiles><smiles>COc1c(O)cc2oc3cc(O)cc([N+](=O)[O-])c3c(=O)c2c1O</smiles><smiles>[R20]c1c(O)cc2oc3cc(OCC)c(CC=C(C)C)c(O)c3c(=O)c2c1CC=C(C)C</smiles><smiles>CC(C)=CCc1c(O)cc2oc3cc(O)c4c(c3c(=O)c2c1O)C=CC(C)(C)O4</smiles>
b $R^{1}=M e, R^{2}=$ Me $\beta$-Mangostin

Fig. 4. Chemical structures of xanthones already studied in LOX and COX assays.

mechanism underlying the effect of xanthones on 5-LOX pathway has been proposed. We can presume that similar to phenolic compounds, xanthones act as redox 5-LOX inhibitors. In fact, this type of 5-LOX inhibition is pointed to the hydroxyxanthone norathyriol $\mathbf{4 a}$ by the results of inhibition of human recombinant 5-LOX activity in a cellfree system [26]. Previous studies suggested that phenolic inhibitors can act at the 5-LOX catalytic domain by reducing the active iron from catalytically active $\mathrm{Fe}$ (III) to the inactive Fe(II) form [31] or by modulation of the hydroperoxide tone [32].

The results from the COX assays showed that the studied 2,3-diarylxanthones were only able to inhibit the COX-1-PGE 2 production stimulated by A23187 in human whole blood, in a concentration-dependent manner, except compound $2 \mathrm{c}$ that was not active up to $100 \mu \mathrm{M}$, the highest tested concentration. The most effective inhibitors in each group of xanthones tested were those non-substituted in ring $\mathrm{D}$, specifically 1a, 2a, and 3a with $\mathrm{IC}_{50}$ values from 1 to $7 \mu \mathrm{M}$. Similar to the results of 5-LOX inhibition, increasing the number of hydroxy groups seems to be disadvantageous in preventing the production of $\mathrm{PGE}_{2}$ catalyzed by $\mathrm{COX}-1$. Indeed, xanthones $\mathbf{2 c}$ (not active) and $\mathbf{3 b}$ (holding three hydroxy groups) and xanthone 3c (with four hydroxy groups) did not reach an $\mathrm{IC}_{50}$ at all. These data are corroborated by Ribeiro et al. that previously found in structuralsimilar compounds, the less substituted flavonoids were those presenting a higher inhibitory activity [22].

This is the first paper that reports the inhibition of COX-1 activity by 2,3-diarylxanthones, but there are a few studies that explore the inhibitory capacity of other substituted xanthones using different experimental conditions. Thus, Hsu et al. tested the inhibitory effect of ram seminal vesicle COX-1 activity in a range of 18 mono, di, tri, and tetraoxygenated xanthones [26]. Norathyriol 4a (Fig. 4) was the most active compound $\left(\mathrm{IC}_{50}=16.2 \pm\right.$ $1.5 \mu \mathrm{M})$, with even higher inhibitory potency than the other three tetrahydroxyxanthones tested. Mono, di, and trihydroxyxanthones were less active than norathyriol, at least with fourfold lower potency. From this study, we can also state that norathyriol 4a showed a similar inhibition of COX-1 and COX-2 activities and a higher efficiency to inhibit human recombinant 5-LOX [26]. The inhibition of ram seminal vesicle COX-1 activity was also examined for furanochromone 5 [29] and trihydroxylated xanthone 6, isolated from the bulbs of Ledebouria ovatifolia [33] (Fig. 4). These compounds displayed minor inhibitory effects of $18.41 \pm 6.50 \%$ at $50 \mu \mathrm{g} / \mathrm{mL}(146 \mu \mathrm{M})$ and 44 $\pm 11 \%$ at $10 \mu \mathrm{M}$, respectively, although xanthone 6 was selective for COX-2 at $10 \mu \mathrm{M}$. $\gamma$-Mangostin 7c, a xanthone present in the fruit hull of mangosteen, and its related compound patulone $\mathbf{8}$ exhibited a similar effect but in higher extent than garcinone B 9 (Fig. 4) on $\mathrm{PGE}_{2}$ release stimulated by $\mathrm{A} 23187$ in $\mathrm{C}_{6}$ rat glioma cells $[34,35]$. The in vitro enzyme assays showed that $\gamma$-mangostin $7 \mathbf{a}$ prevented, in a concentration-dependent manner, both COX-1 $\left(\mathrm{IC}_{50}=0.8 \mu \mathrm{M}\right)$ and COX-2 $\left(\mathrm{IC}_{50}=2 \mu \mathrm{M}\right)$ activities [34] as well as patulone 8 (Fig. 4) had the ability to prevent the enzymatic activity of COX-1 [35].

Although none of the studied 2,3-arylxanthones 1-3 were able to prevent the COX-2- $\mathrm{PGE}_{2}$ production stimulated by LPS in human whole blood, there are several reports highlighting the preventive effects of several xanthones against COX-2 activity. Garrido et al. studied the LPS-interferon gamma-induced $\mathrm{PGE}_{2}$ release by mangiferin $\mathbf{4 b}$ in $\mathrm{J} 774$ murine macrophage cell lines that 
showed a high inhibitory activity with an $\mathrm{IC}_{50}$ value of $17.2 \mu \mathrm{g} / \mathrm{mL}$ [27]. Using RAW264.7 macrophage cells, the inhibitory potency of $\alpha$-mangostin $7 \mathbf{a}\left(\mathrm{IC}_{50}=13.9 \mu \mathrm{g} / \mathrm{mL}\right)$ and $\gamma$-mangostin $7 \mathbf{c}\left(\mathrm{IC}_{50}=13.5 \mu \mathrm{g} / \mathrm{mL}\right)$ was also very significant [36] while $\beta$-mangostin $\mathbf{7 b}$ proved to be a selective inhibitor of COX-2 $(53.0 \pm 6.0 \%$ inhibition at $20 \mu \mathrm{g} / \mathrm{mL}$ ), with a slight effect on COX-1 activity (17.1 $\pm 1.0 \%$ inhibition at $20 \mu \mathrm{g} / \mathrm{mL}$ ) [37]. A similar behavior was observed for furanoxanthone 5 tested in a concentration of $50 \mu \mathrm{g} / \mathrm{mL}$ where the results pointed to a moderate inhibition of COX-2 activity $(36.15 \pm 4.68 \%)$ and a slight inhibition of COX-1 activity $(18.41 \pm 6.50 \%)$ [29]. This short results seem to indicate that xanthones bearing oxygenated substituents and lipophilic carbon chains are good candidates as COX-2 inhibitors.

\section{CONCLUSION}

In this study, for the first time, a range of 2,3diarylxanthones showed to suppress $\mathrm{LTB}_{4}$ production induced by A23187 and AA in human neutrophils, in a concentrationdependent manner. The results point out to an inhibition in a range of 36 to $71 \%$, at $20 \mu \mathrm{M}$, the highest tested concentration. The most active one was xanthone 1c with a 2-catechol group presenting an $\mathrm{IC}_{50}$ value around $9 \mu \mathrm{M}$.

The 2,3-diarylxanthones were also tested for their ability to inhibit $\mathrm{PGE}_{2}$ production stimulated by $\mathrm{A} 23187$ and LPS in human whole blood. At $10 \mu \mathrm{M}$ concentration, xanthones 1a, 1b, 2a, and 3a (possessing at least one nonsubstituted aryl group) exhibited COX-1 inhibitory effects higher than $50 \%$ and with $\mathrm{IC}_{50}$ values from 1 to $7 \mu \mathrm{M}$. The COX-2 activity was unaffected by the 2,3-diarylxanthones, up to the highest tested concentration, $100 \mu \mathrm{M}$. In conclusion, the 2,3-diarylxanthones studied had a dual impact on the 5-LOX and COX-1 activities, an important contribution to reinforce the potential of this class of heterocyclic compounds in the modulation of the production of inflammatory mediators and it challenges to pursuit for novel structures with improved selectivity in the inflammatory cascade.

\section{ACKNOWLEDGEMENTS}

Sincere thanks are expressed to Faculdade de Farmácia da Universidade do Porto, Universidade de Aveiro, Instituto Politécnico de Bragança, Fundação para a Ciência e a Tecnologia (FCT, Portugal), Ministério da Educação e Ciência, European Union, FEDER, PT 2020, QREN, and COMPETE funding UCIBIO, REQUIMTE [(PT2020 UID/MULTI/04378/2013 - POCI/01/0145/
FEDER/007728), (NORTE-01-0145-FEDER-000024), and (PTDC/QEQ-QAN/1742/2014 - POCI-01-0145FEDER-016530)] and QOPNA (FCT UID/QUI/00062/ 2013) Research Units and also to the Portuguese National NMR Network (RNRMN). We gratefully acknowledge Graça Porto and the nursing staff of the Centro Hospitalar do Porto - Hospital de Santo António blood bank for the collaboration in the recruitment of blood donors involved in the present work.

\section{REFERENCES}

1. Ribeiro, D., M. Freitas, J.L.F.C. Lima, and E. Fernandes. 2015. Proinflammatory pathways: the modulation by flavonoids. Medicinal Research Reviews 35: 877-936.

2. Krishnamoorthy, S., and K.V. Honn. 2006. Inflammation and disease progression. Cancer and Metastasis Reviews 25: 481-491.

3. Williams, C.S., M. Mann, and R.N. DuBois. 1999. The role of cyclooxygenases in inflammation, cancer, and development. Oncogene 18: 7908-7916.

4. Bertolini, A., A. Ottani, and M. Sandrini. 2002. Selective COX-2 inhibitors and dual acting anti-inflammatory drugs: critical remarks. Current Medicinal Chemistry 9: 1033-1043.

5. Leone, S., A. Ottani, and A. Bertolini. 2007. Dual acting antiinflammatory drugs. Current Topics in Medicinal Chemistry 7: 265-275.

6. Fiorucci, S., R. Meli, M. Bucci, and G. Cirino. 2001. Dual inhibitors of cyclooxygenase and 5-lipoxygenase. A new avenue in antiinflammatory therapy? Biochemical Pharmacology 62: 1433-1438.

7. El-Seedi, H.R., D.M.N. El-Ghorab, M.A. El-Barbary, and M.F. Zayed. 2009. Naturally occurring xanthones; latest investigations: isolation, structure elucidation and chemosystematic significance. Current Medicinal Chemistry 16: 2581-2626.

8. Panda, S.S., M. Chand, R. Sakhuja, and S.C. Jain. 2013. Xanthones as potential antioxidants. Current Medicinal Chemistry 20: 44814507.

9. Negi, J.S., V.K. Bisht, P. Singh, M.S.M. Rawat, and G.P. Joshi. 2013. Naturally occurring xanthones: chemistry and biology. Journal of Applied Chemistry 2013: 1-9.

10. El-Seedi, H.R., M.A. El-Barbary, D.M.H. El-Ghorab, L. Bohlin, A.K. Borg-Karlson, et al. 2010. Recent insights into the biosynthesis and biological activities of natural xanthones. Current Medicinal Chemistry 17: 854-901.

11. Pinto, M.M.M., M.E. Sousa, and M.S.J. Nascimento. 2005. Xanthone derivatives: new insights in biological activities. Current Medicinal Chemistry 12: 2517-2538.

12. Jiang, D.-J., Z. Dai, and Y.-J. Li. 2004. Pharmacological effects of xanthones as cardiovascular protective agents. Cardiovascular Drug Reviews 22: 91-102.

13. Santos, C.M.M., D.C.G.A. Pinto, V.L.M. Silva, and A.M.S. Silva. 2016. Arylxanthones and arylacridones: a synthetic overview. Pure and Applied Chemistry 88: 579-594.

14. Santos, C.M.M., M. Freitas, D. Ribeiro, A. Gomes, A.M.S. Silva, et al. 2010. 2,3-Diarylxanthones as strong scavengers of reactive oxygen and nitrogen species: a structure-activity relationship study. Bioorganic and Medicinal Chemistry 18: 6776-6784. 
15. Proença, C., H.M.T. Albuquerque, D. Ribeiro, M. Freitas, C.M.M. Santos, et al. 2016. Novel chromone and xanthone derivatives: synthesis and ROS/RNS scavenging activities. European Journal of Medicinal Chemistry 115: 381-392.

16. Santos, C.M.M., A.M.S. Silva, P. Filipe, R. Santus, L.K. Patterson, et al. 2011. Structure-activity relationships in hydroxy-2,3diarylxanthone antioxidants. Fast kinetics spectroscopy as a tool to evaluate the potential for antioxidant activity in biological systems. Organic and Biomolecular Chemistry 9: 3965-3974.

17. Carvalho, L.C.R., D. Ribeiro, R.S.G.R. Seixas, A.M.S. Silva, M. Nave, et al. 2015. Synthesis and evaluation of new benzimidazole based COX inhibitors: a naproxen-like interaction detected by STDNMR. RSC Advances 5: 49098-49109.

18. Santos, C.M.M., A.M.S., Silva, and J.A.S., Cavaleiro. 2009. Efficient syntheses of new polyhydroxylated 2,3-diaryl-9H-xanthen-9ones. European Journal of Organic Chemistry 2009: 2642-2660.

19. Freitas, M., G. Porto, J.L. Lima, and E. Fernandes. 2008. Isolation and activation of human neutrophils in vitro. The importance of the anticoagulant used during blood collection. Clinical Biochemistry 41: $570-575$.

20. Gomes, A., E. Fernandes, A.M.S. Silva, D.C.G.A. Pinto, C.M.M. Santos, et al. 2009. Anti-inflammatory potential of 2styrylchromones regarding their interference with arachidonic acid metabolic pathways. Biochemical Pharmacology 78: 171-177.

21. Laufer, S., and S. Luik. 2010. Different methods for testing potential cyclooxygenase-1 and cyclooxygenase-2 inhibitors. In: Ayoub SS, editor. Cyclooxygenases: methods and protocols, 644th ed, 91-116. Philadelphia: Springer Science + Business Media, LLC.

22. Ribeiro, D., M. Freitas, S.M. Tomé, A.M.S. Silva, S. Laufer, et al. 2015. Flavonoids inhibit COX-1 and COX-2 enzymes and cytokine/ chemokine production in human whole blood. Inflammation 38 : 858-870.

23. Laufer, S., C. Greim, S. Luik, S.S. Ayoub, and F. Dehner. 2008. Human whole blood assay for rapid and routine testing of nonsteroidal anti-inflammatory drugs (NSAIDs) on cyclo-oxygenase-2 activity. Inflammopharmacology 16: 155-161.

24. Ribeiro, D., M. Freitas, S.M. Tomé, A.M.S. Silva, G. Porto, et al. 2014. Inhibition of LOX by flavonoids: a structure-activity relationship study. European Journal of Medicinal Chemistry 72: 137-145.

25. Sadik, C.D., H. Sies, and T. Schewe. 2003. Inhibition of 15lipoxygenases by flavonoids: structure-activity relations and mode of action. Biochemical Pharmacology 65: 773-781.

26. Hsu, M.-F., C.-N. Lin, M.-C. Lu, and J.-P. Wang. 2004. Inhibition of the arachidonic acid cascade by norathyriol via blockade of cyclooxygenase and lipoxygenase activity in neutrophils. NaunynSchmiedeberg's Archives in Pharmacolology 369: 507-515.

27. Garrido, G., D. González, Y. Lemus, C. Delporte, and R. Delgado. 2006. Protective effects of a standard extract of Mangifera indica $\mathrm{L}$. (VIMANGs) against mouse ear edemas and its inhibition of eicosanoid production in J774 murine macrophages. Phytomedicine 13: 412-418.

28. Garrido, G., D. González, Y. Lemus, D. García, L. Lodeiro, et al. 2004. In vivo and in vitro anti-inflammatory activity of Mangifera indica L. extract (VIMANG®). Pharmarcological Research 50: 143-149.

29. Crockett, S.L., B. Poller, N. Tabanca, E.-M. Pferschy-Wenzig, O. Kunert, et al. 2011. Bioactive xanthones from the roots of Hypericum perforatum (common St John's wort). Journal of the Science Food Agriculture 91: 428-434.

30. Werz, O., and D. Steinhilber. 2005. Development of 5-lipoxygenase inhibitors-lessons from cellular enzyme regulation. Biochemical Pharmacology 70: 327-333.

31. Nelson, M.J., D.G. Batt, J.S. Thompson, and S.W. Wright. 1991. Reduction of the active-site iron by potent inhibitors of lipoxygenases. Journal of Biological Chemistry 266: 8225-8229.

32. Rouzer, C.A., and B., Samuelsson. 1986. The importance of hydroperoxide activation for the detection and assay of mammalian 5lipoxygenase. FEBS Letters 204: 293-296.

33. Waller, C.P., A.E. Thumser, M.K. Langat, N.R. Crouch, and D.A. Mulholland. 2013. COX-2 inhibitory activity of homoisoflavanones and xanthones from the bulbs of the southern African Ledebouria socialis and Ledebouria ovatifolia (Hyacinthaceae: Hyacinthoideae). Phytochemistry 95: 284-290.

34. Nakatani, K., N. Nakahata, T. Arakawa, H. Yasuda, and Y. Ohizumi. 2002. Inhibition of cyclooxygenase and prostaglandin $E_{2}$ synthesis by $\gamma$-mangostin, a xanthone derivative in mangosteen, in C6 rat glioma cells. Biochemical Pharmacology 63: 73-79.

35. Yamakuni, T., K. Aoki, K. Nakatani, N. Kondo, H. Oku, et al. 2006. Garcinone $\mathrm{B}$ reduces prostaglandin $\mathrm{E}_{2}$ release and NF-kB-mediated transcription in C6 rat glioma cells. Neuroscience Letters 394: 206-210.

36. Tewtrakul, S., C. Wattanapiromsakul, and W. Mahabusarakam. 2009. Effects of compounds from Garcinia mangostana on inflammatory mediators in RAW264.7 macrophage cells. Journal of Ethnopharmacology 121: 379-382.

37. Syam, S., A. Bustamam, R. Abdullah, M.A. Sukari, N.M. Hashim, et al. 2014. $\beta$ Mangostin suppress LPS-induced inflammatory response in RAW 264.7 macrophages in vitro and carrageenaninduced peritonitis in vivo. Journal of Ethnopharmacology 153: $435-445$. 